\title{
Shrinking Projection Methods for Split Common Fixed-Point Problems in Hilbert Spaces
}

\author{
Huan-chun Wu and Cao-zong Cheng \\ College of Applied Sciences, Beijing University of Technology, Beijing 100124, China \\ Correspondence should be addressed to Huan-chun Wu; wuhuanchun@emails.bjut.edu.cn
}

Received 19 December 2013; Accepted 2 April 2014; Published 14 April 2014

Academic Editor: Satit Saejung

Copyright (C) 2014 H.-c. Wu and C.-z. Cheng. This is an open access article distributed under the Creative Commons Attribution License, which permits unrestricted use, distribution, and reproduction in any medium, provided the original work is properly cited.

Inspired by Moudafi (2011) and Takahashi et al. (2008), we present the shrinking projection method for the split common fixedpoint problem in Hilbert spaces, and we obtain the strong convergence theorem. As a special case, the split feasibility problem is also considered.

\section{Introduction}

Let $C$ and $Q$ be nonempty closed convex sets in real Hilbert spaces $H_{1}$ and $H_{2}$, respectively. The split feasibility problem (SFP) is to find

$$
x \in C, \quad \text { such that } A x \in Q \text {, }
$$

where $A: H_{1} \rightarrow H_{2}$ is a bounded linear operator. We use $\Phi$ to denote the solution set of the SFP (1). The SFP in finite-dimensional Hilbert space was first introduced by Censor and Elfving [1]. In 2010, Xu [2] considered the SFP in the setting of infinite-dimensional Hilbert space. The SFP has received much attention due to its wide applications in signal processing, image reconstruction, intensity-modulated radiation therapy, and so on (see [3-6]). Several iterative methods can be used to solve the SFP (1). Censor and Elfving [1] constructed the iterative process which involves the computation of the inverse of a matrix. A more popular algorithm that solves the SFP is the CQ algorithm of Byrne $[3,4]$; that is, let $x_{0}$ be an arbitrary point in $H_{1}$ :

$$
x_{n+1}=P_{C}\left(I-\gamma A^{*}\left(I-P_{\mathrm{Q}}\right) A\right) x_{n},
$$

where $\gamma>0$ is a parameter and $P_{C}$ and $P_{Q}$ are metric projections onto $C$ and $Q$, respectively.

Let $K$ be a nonempty closed convex subset of a real Hilbert space $H$ and let $T: K \rightarrow K$ be a mapping. We denote by $\operatorname{Fix}(T)$ the fixed-point set of $T$; that is, $\operatorname{Fix}(T)=$ $\{x \in K: T x=x\}$. A mapping $T: K \rightarrow K$ is nonexpansive if $\|T x-T y\| \leq\|x-y\|$ forall $x, y \in K$. A mapping $T: K \rightarrow K$ is quasinonexpansive if $\operatorname{Fix}(T) \neq \emptyset$ and $\|T x-y\| \leq\|x-y\|$ forall $x \in K$ and $y \in \operatorname{Fix}(T)$. It is known that the fixed-point set of a quasinonexpansive mapping is closed and convex (see $[7,8])$. There are some quasinonexpansive mappings which are not nonexpansive (see [9-11]). For example, the level set of a continuous convex function is characterized as the fixed-point set of a nonlinear mapping called the subgradient projection, which is not nonexpansive but quasinonexpansive.

Now we focus our attention on the following twooperator split common fixed-point problem (SCFP):

$$
\text { find } x^{*} \in C \text {, such that } A x^{*} \in Q \text {, }
$$

where $A: H_{1} \rightarrow H_{2}$ is a bounded linear operator and $U$ : $H_{1} \rightarrow H_{1}$ and $T: H_{2} \rightarrow H_{2}$ are two quasinonexpansive mappings with $\operatorname{Fix}(U)=C$ and $\operatorname{Fix}(T)=Q$. The solution set of the SCFP (3) is denoted by

$$
\Gamma=\left\{x^{*} \in C: A x^{*} \in Q\right\} .
$$

As far as we know, the SCFP is introduced by Censor and Segal [12]. By taking $U=P_{C}$ and $T=P_{\mathrm{Q}}$, the SCFP reduces to the SFP. Hence, the SCFP is a generalization of the SFP. Moudafi [13] considered the following algorithm for the 
SCFP: let $x_{0} \in H_{1}$ be arbitrary, $u_{k}=x_{k}-\gamma \beta A^{*}(I-T) A x_{k}$ and

$$
x_{k+1}=\left(1-\alpha_{k}\right) u_{k}+\alpha_{k} U\left(u_{k}\right) \text {, }
$$

where $\beta \in(0,1), \alpha_{k} \in(0,1)$, and $\gamma \in(0,1 / \lambda \beta)$, with $\lambda$ being the spectral radius of the operator $A^{*} A$. He obtained the weak convergence of the algorithm (5).

In 2008, Takahashi et al. [14] developed the shrinking projection method for the nonexpansive mapping. Let $T$ be a nonexpansive mapping of $K$ into itself such that $\operatorname{Fix}(T) \neq \emptyset$. Let $x_{0} \in H, C_{1}=K$ and $u_{1}=P_{C_{1}} x_{0}$;

$$
\begin{aligned}
y_{n} & =\alpha_{n} u_{n}+\left(1-\alpha_{n}\right) T u_{n}, \\
C_{n+1} & =\left\{z \in C_{n}:\left\|y_{n}-z\right\| \leq\left\|u_{n}-z\right\|\right\}, \\
u_{n+1} & =P_{C_{n+1}} x_{0},
\end{aligned}
$$

where $0 \leq \alpha_{n} \leq a<1$. They proved that the sequence $\left\{u_{n}\right\}$ converges strongly to $P_{\mathrm{Fix}(T)} x_{0}$.

Motivated by the above results, especially by Moudafi [13] and Takahashi et al. [14], in this paper, we present the shrinking projection methods for the split common fixedpoint problems. As a special case, the split feasibility problem is also discussed.

\section{Preliminaries}

Throughout this paper, let $\mathbb{N}$ and $\mathbb{R}$ be the sets of positive integers and real numbers, respectively. For any $x \in H$, there exists a unique point $P_{K} x \in K$ such that

$$
\left\|x-P_{K} x\right\| \leq\|x-y\| \quad \forall y \in K,
$$

where $K$ is a nonempty closed convex subset of a real Hilbert space $H$. The mapping $P_{K}$ is called the metric projection of $H$ onto $K$. Note that $P_{K}$ is a nonexpansive mapping. For $x \in H$ and $z \in K$, we have

$$
z=P_{K} x \Longleftrightarrow\langle x-z, y-z\rangle \leq 0 \text { for every } y \in K \text {. }
$$

We say that a mapping $T: K \rightarrow K$ is demiclosed at zero if for any sequence $\left\{x_{n}\right\} \subset K$ which converges weakly to $x$, the strong convergence of the sequence $\left\{T x_{n}\right\}$ to zero implies that $T x=0$. It is well known that $I-T$ is demiclosed whenever $T$ is nonexpansive. In fact, this property is satisfied for more general mappings (see $[15,16]$ ).

We will use the following notations:

(1) $x_{n} \rightarrow x$ stands for the strong convergence of $\left\{x_{n}\right\}$ to $x$

(2) $x_{n} \rightarrow x$ stands for the weak convergence of $\left\{x_{n}\right\}$ to $x$;

(3) $\omega_{\omega}\left(x_{n}\right)=\left\{x: \exists x_{n_{j}} \rightarrow x\right\}$ denotes the weak $\omega$-limit set of $\left\{x_{n}\right\}$.

Here are two useful lemmas.

Lemma 1. Let $x, y \in H$ and let $\lambda \in \mathbb{R}$. One has

$$
\begin{aligned}
& \|\lambda x+(1-\lambda) y\|^{2} \\
& =\lambda\|x\|^{2}+(1-\lambda)\|y\|^{2}-\lambda(1-\lambda)\|x-y\|^{2} .
\end{aligned}
$$

Lemma 2 (see [17]). Let $K$ be a closed convex subset of a real Hilbert space $H$ and let $\left\{x_{n}\right\}$ be a sequence in $H$ and $u \in H$. Let $q=P_{K} u$. If $\left\{x_{n}\right\}$ satisfies the following conditions:

(1) $\omega_{\omega}\left(x_{n}\right) \subset K$,

(2) $\left\|x_{n}-u\right\| \leq\|u-q\|$ for all $n \in \mathbb{N}$,

then one has $x_{n} \rightarrow q$.

\section{Shrinking Projection Methods}

Now we are in a position to give the shrinking projection method for split common fixed-point problem (3).

Theorem 3. Let $H_{1}$ and $H_{2}$ be real Hilbert spaces and let $A$ : $H_{1} \rightarrow H_{2}$ be a bounded linear operator. Let $U: H_{1} \rightarrow H_{1}$ and $\mathrm{T}: \mathrm{H}_{2} \rightarrow \mathrm{H}_{2}$ be two quasinonexpansive mappings with $\operatorname{Fix}(U)=C$ and $\operatorname{Fix}(T)=Q$. Suppose that $I-U$ and $I-$ $T$ are demiclosed at zero and solution set $\Gamma$ of the SCFP (3) is nonempty. For $u \in H_{1}$ chosen arbitrarily, $C_{1}=H_{1}, h_{1}=P_{C_{1}} u$, define a sequence $\left\{h_{n}\right\}$ by the following algorithm:

$$
\begin{aligned}
w_{n} & =h_{n}-\gamma A^{*}(I-T) A h_{n}, \\
y_{n} & =\alpha_{n} w_{n}+\left(1-\alpha_{n}\right) U w_{n}, \\
C_{n+1} & =\left\{z \in C_{n}:\left\|y_{n}-z\right\| \leq\left\|h_{n}-z\right\|\right\}, \\
h_{n+1} & =P_{C_{n+1}} u .
\end{aligned}
$$

If the following are satisfied:

(1) $\left\{\alpha_{n}\right\} \subset(0,1)$ and $\liminf _{n \rightarrow \infty} \alpha_{n}\left(1-\alpha_{n}\right)>0$,

(2) $0<\gamma<\left(1 / \lambda_{A A^{*}}\right)$, where $\lambda_{A A^{*}}$ denotes the spectral radius of the operator $A A^{*}$,

then the sequence $\left\{h_{n}\right\}$ converges strongly to $P_{\Gamma} u$.

Proof. We first show that $\Gamma \subset C_{n}$ for all $n \in \mathbb{N}$. It is obvious that $\Gamma$ is contained in $C_{1}=H_{1}$. Suppose that $\Gamma \subset C_{k}$ for some $k \in \mathbb{N}$. We have, for any $p \in \Gamma \subset C_{k}$,

$$
\begin{aligned}
&\left\|y_{k}-p\right\|^{2} \\
&=\left\|\alpha_{k} w_{k}+\left(1-\alpha_{k}\right) U w_{k}-p\right\|^{2} \\
& \leq \alpha_{k}\left\|w_{k}-p\right\|^{2}+\left(1-\alpha_{k}\right)\left\|w_{k}-p\right\|^{2} \\
&=\left\|h_{k}-\gamma A^{*}(I-T) A h_{k}-p\right\|^{2} \\
&=\left\|h_{k}-p\right\|^{2}-2 \gamma\left\langle A^{*}(I-T) A h_{k}, h_{k}-p\right\rangle \\
&+\gamma^{2}\left\|A^{*}(I-T) A h_{k}\right\|^{2} \\
&=\left\|h_{k}-p\right\|^{2}+2 \gamma\left\langle T A h_{k}-A h_{k}, A h_{k}-A p\right\rangle
\end{aligned}
$$




$$
\begin{aligned}
& +\gamma^{2}\left\langle(I-T) A h_{k}, A A^{*}(I-T) A h_{k}\right\rangle \\
\leq & \left\|h_{k}-p\right\|^{2}+\gamma^{2} \lambda_{A A^{*}}\left\|(I-T) A h_{k}\right\|^{2} \\
& +\gamma\left[\left\|T A h_{k}-A p\right\|^{2}-\left\|T A h_{k}-A h_{k}\right\|^{2}-\left\|A h_{k}-A p\right\|^{2}\right] \\
\leq & \left\|h_{k}-p\right\|^{2}+\gamma^{2} \lambda_{A A^{*}}\left\|(I-T) A h_{k}\right\|^{2} \\
& -\gamma\left\|T A h_{k}-A h_{k}\right\|^{2} \\
= & \left\|h_{k}-p\right\|^{2}+\gamma\left(\gamma \lambda_{A A^{*}}-1\right)\left\|(I-T) A h_{k}\right\|^{2} \\
\leq & \left\|h_{k}-p\right\|^{2} .
\end{aligned}
$$

It follows that $p \in C_{k+1}$. Thus, we get $\Gamma \subset C_{n}$ for all $n \in \mathbb{N}$.

Next we show that $C_{n}$ is closed and convex for all $n \in \mathbb{N}$. The set $C_{1}=H_{1}$ is obviously closed and convex. Suppose that $C_{k}$ is closed and convex. We see that $C_{k+1}$ is closed and convex since $\left\|y_{n}-z\right\| \leq\left\|h_{n}-z\right\|$ is equivalent to

$$
\left\|y_{n}\right\|^{2}-\left\|h_{n}\right\|^{2}-2\left\langle y_{n}-h_{n}, z\right\rangle \leq 0 .
$$

It follows that $C_{n}$ is closed and convex for all $n \in \mathbb{N}$. Therefore, we obtain that the sequence $\left\{h_{n}\right\}$ is well defined.

From $h_{n}=P_{C_{n}} u$, we have

$$
\left\langle u-h_{n}, h_{n}-y\right\rangle \geq 0 \quad \forall y \in C_{n} .
$$

Recalling that $\Gamma \subset C_{n}$, one has

$$
\left\langle u-h_{n}, h_{n}-p\right\rangle \geq 0 \quad \forall p \in \Gamma .
$$

Hence,

$$
\begin{aligned}
0 & \leq\left\langle u-h_{n}, h_{n}-p\right\rangle \\
& =\left\langle u-h_{n}, h_{n}-u+u-p\right\rangle \\
& \leq-\left\|u-h_{n}\right\|^{2}+\left\|u-h_{n}\right\|\|u-p\| .
\end{aligned}
$$

This implies that

$$
\left\|u-h_{n}\right\| \leq\|u-p\|,
$$

which yields that $\left\{h_{n}\right\}$ is bounded.

From $h_{n}=P_{C_{n}} u$ and $h_{n+1}=P_{C_{n+1}} u \in C_{n+1} \subset C_{n}$, we get

$$
\begin{aligned}
0 & \leq\left\langle u-h_{n}, h_{n}-h_{n+1}\right\rangle \\
& \leq-\left\|u-h_{n}\right\|^{2}+\left\|u-h_{n}\right\|\left\|u-h_{n+1}\right\|,
\end{aligned}
$$

which gives that

$$
\left\|u-h_{n}\right\| \leq\left\|u-h_{n+1}\right\| .
$$

Hence,

$$
\text { the limit } \lim _{n \rightarrow \infty}\left\|u-h_{n}\right\| \text { exists. }
$$

It follows from (17) that

$$
\begin{aligned}
\| h_{n}- & h_{n+1} \|^{2} \\
= & \left\|h_{n}-u\right\|^{2}+2\left\langle h_{n}-u, u-h_{n+1}\right\rangle \\
& +\left\|u-h_{n+1}\right\|^{2} \\
= & \left\|h_{n}-u\right\|^{2}+2\left\langle h_{n}-u, u-h_{n}+h_{n}-h_{n+1}\right\rangle \\
& +\left\|u-h_{n+1}\right\|^{2} \\
= & -\left\|h_{n}-u\right\|^{2}+2\left\langle h_{n}-u, h_{n}-h_{n+1}\right\rangle \\
& +\left\|u-h_{n+1}\right\|^{2} \\
\leq & -\left\|h_{n}-u\right\|^{2}+\left\|u-h_{n+1}\right\|^{2} .
\end{aligned}
$$

Thus, we get

$$
\lim _{n \rightarrow \infty}\left\|h_{n}-h_{n+1}\right\|=0 .
$$

The fact that $h_{n+1}=P_{C_{n+1}} u \in C_{n+1}$ gives

$$
\left\|y_{n}-h_{n+1}\right\| \leq\left\|h_{n}-h_{n+1}\right\| \longrightarrow 0 .
$$

The expressions (21) and (22) yield

$$
\lim _{n \rightarrow \infty}\left\|y_{n}-h_{n}\right\|=0 .
$$

We will prove that $\omega_{\omega}\left(h_{n}\right) \subset \Gamma$. Without loss of generality, we assume that $h_{n} \rightarrow h^{*}$. It follows from (11) that

$$
\begin{aligned}
& \gamma\left(1-\gamma \lambda_{A A^{*}}\right)\left\|(I-T) A h_{n}\right\|^{2} \\
& \quad \leq\left\|h_{n}-p\right\|^{2}-\left\|y_{n}-p\right\|^{2} \\
& \quad \leq\left(\left\|h_{n}-p\right\|+\left\|y_{n}-p\right\|\right)\left\|h_{n}-y_{n}\right\| .
\end{aligned}
$$

This together with (23) implies that

$$
\lim _{n \rightarrow \infty}\left\|(I-T) A h_{n}\right\|=0 .
$$

We have $A h^{*} \in \operatorname{Fix}(T)=Q$ since $I-T$ is demiclosed at zero. Using (??) and (25), we get $w_{n} \rightarrow h^{*}$. For any $p \in \Gamma$, one has

$$
\begin{aligned}
&\left\|y_{n}-p\right\|^{2} \\
&=\left\|\alpha_{n} w_{n}+\left(1-\alpha_{n}\right) U w_{n}-p\right\|^{2} \\
&= \alpha_{n}\left\|w_{n}-p\right\|^{2}+\left(1-\alpha_{n}\right)\left\|U w_{n}-p\right\|^{2} \\
&-\alpha_{n}\left(1-\alpha_{n}\right)\left\|U w_{n}-w_{n}\right\|^{2} \\
& \leq\left\|w_{n}-p\right\|^{2}-\alpha_{n}\left(1-\alpha_{n}\right)\left\|U w_{n}-w_{n}\right\|^{2} \\
& \leq\left\|h_{n}-p\right\|^{2}-\alpha_{n}\left(1-\alpha_{n}\right)\left\|U w_{n}-w_{n}\right\|^{2},
\end{aligned}
$$


which implies that

$$
\begin{aligned}
& \alpha_{n}\left(1-\alpha_{n}\right)\left\|U w_{n}-w_{n}\right\|^{2} \\
& \quad \leq\left\|h_{n}-p\right\|^{2}-\left\|y_{n}-p\right\|^{2} \\
& \quad \leq\left(\left\|h_{n}-p\right\|+\left\|y_{n}-p\right\|\right)\left\|h_{n}-y_{n}\right\| .
\end{aligned}
$$

Therefore, one has

$$
\lim _{n \rightarrow \infty}\left\|U w_{n}-w_{n}\right\|=0
$$

It follows that $h^{*} \in \operatorname{Fix}(U)=C$ since $I-U$ is demiclosed at zero. Thus, we have obtained $\omega_{\omega}\left(h_{n}\right) \in \Gamma$. According to Lemma 2, we see that $h_{n} \rightarrow P_{\Gamma} u$.

By Theorem 3, we immediately obtain the shrinking projection method for the split feasibility problem.

Theorem 4. Let $H_{1}$ and $H_{2}$ be real Hilbert spaces and let $C$ and $Q$ be nonempty closed convex subsets of $H_{1}$ and $H_{2}$, respectively. Let $A: H_{1} \rightarrow H_{2}$ be a bounded linear operator. Suppose that the solution set $\Phi$ of the SFP (1) is nonempty. For $u \in H_{1}$ chosen arbitrarily, $C_{1}=H_{1}, h_{1}=P_{C_{1}} u$, define a sequence $\left\{h_{n}\right\}$ by the following algorithm:

$$
\begin{aligned}
w_{n} & =h_{n}-\gamma A^{*}\left(I-P_{\mathrm{Q}}\right) A h_{n}, \\
y_{n} & =\alpha_{n} w_{n}+\left(1-\alpha_{n}\right) P_{C} w_{n}, \\
C_{n+1} & =\left\{z \in C_{n}:\left\|y_{n}-z\right\| \leq\left\|h_{n}-z\right\|\right\}, \\
h_{n+1} & =P_{C_{n+1}} u .
\end{aligned}
$$

If the following are satisfied:

(1) $\left\{\alpha_{n}\right\} \subset(0,1)$ and $\liminf _{n \rightarrow \infty} \alpha_{n}\left(1-\alpha_{n}\right)>0$,

(2) $0<\gamma<1 / \lambda_{A A^{*}}$, where $\lambda_{A A^{*}}$ denotes the spectral radius of the operator $A A^{*}$,

then the sequence $\left\{h_{n}\right\}$ converges strongly to $P_{\Phi} u$.

Remark 5. Letting $u=0$ in Theorems 3 and 4 , we obtain the shrinking projection methods for minimum-norm solutions of corresponding problems.

\section{Conflict of Interests}

The authors declare that there is no conflict of interests regarding the publication of this paper.

\section{Acknowledgments}

The authors would like to thank the referees and editors for their valuable comments and suggestions.

\section{References}

[1] Y. Censor and T. Elfving, "A multiprojection algorithm using Bregman projections in a product space," Numerical Algorithms, vol. 8, no. 2, pp. 221-239, 1994.

[2] H.-K. Xu, "Iterative methods for the split feasibility problem in infinite-dimensional Hilbert spaces," Inverse Problems, vol. 26, no. 10, Article ID 105018, 17 pages, 2010.

[3] C. Byrne, "Iterative oblique projection onto convex sets and the split feasibility problem," Inverse Problems, vol. 18, no. 2, pp. 441453, 2002.

[4] C. Byrne, "A unified treatment of some iterative algorithms in signal processing and image reconstruction," Inverse Problems, vol. 20, no. 1, pp. 103-120, 2004.

[5] Y. Censor, T. Bortfeld, B. Martin, and A. Trofimov, "A unified approach for inversion problems in intensity-modulated radiation therapy," Physics in Medicine and Biology, vol. 51, no. 10, pp. 2353-2365, 2006.

[6] Y. Censor and G. T. Herman, "On some optimization techniques in image reconstruction from projections," Applied Numerical Mathematics, vol. 3, no. 5, pp. 365-391, 1987.

[7] S. Itoh and W. Takahashi, "The common fixed point theory of singlevalued mappings and multivalued mappings," Pacific Journal of Mathematics, vol. 79, no. 2, pp. 493-508, 1978.

[8] P. Kocourek, W. Takahashi, and J.-C. Yao, "Fixed point theorems and weak convergence theorems for generalized hybrid mappings in Hilbert spaces," Taiwanese Journal of Mathematics, vol. 14, no. 6, pp. 2497-2511, 2010.

[9] I. Yamada and N. Ogura, "Hybrid steepest descent method for variational inequality problem over the fixed point set of certain quasi-nonexpansive mappings," Numerical Functional Analysis and Optimization, vol. 25, no. 7-8, pp. 619-655, 2004.

[10] P. L. Combettes and J. C. Pesquet, "Image restoration subject to a total variation constraint," IEEE Transactions on Image Processing, vol. 13, no. 9, pp. 1213-1222, 2004.

[11] G. E. Kim, "Weak and strong convergence theorems of quasinonexpansive mappings in a Hilbert spaces," Journal of Optimization Theory and Applications, vol. 152, no. 3, pp. 727-738, 2012.

[12] Y. Censor and A. Segal, "The split common fixed point problem for directed operators," Journal of Convex Analysis, vol. 16, no. 2, pp. 587-600, 2009.

[13] A. Moudafi, "A note on the split common fixed-point problem for quasi-nonexpansive operators," Nonlinear Analysis: Theory, Methods \& Applications, vol. 74, no. 12, pp. 4083-4087, 2011.

[14] W. Takahashi, Y. Takeuchi, and R. Kubota, "Strong convergence theorems by hybrid methods for families of nonexpansive mappings in Hilbert spaces," Journal of Mathematical Analysis and Applications, vol. 341, no. 1, pp. 276-286, 2008.

[15] G. Marino and H.-K. Xu, "Weak and strong convergence theorems for strict pseudo-contractions in Hilbert spaces," Journal of Mathematical Analysis and Applications, vol. 329, no. 1, pp. 336-346, 2007.

[16] L.-J. Lin, C.-S. Chuang, and Z.-T. Yu, "Fixed point theorems for some new nonlinear mappings in Hilbert spaces," Fixed Point Theory and Applications, vol. 2011, article 51, 2011.

[17] C. Martinez-Yanes and H.-K. Xu, "Strong convergence of the CQ method for fixed point iteration processes," Nonlinear Analysis: Theory, Methods \& Applications, vol. 64, no. 11, pp. 2400-2411, 2006. 


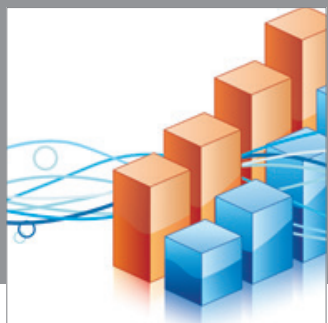

Advances in

Operations Research

mansans

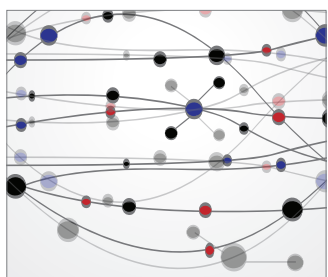

The Scientific World Journal
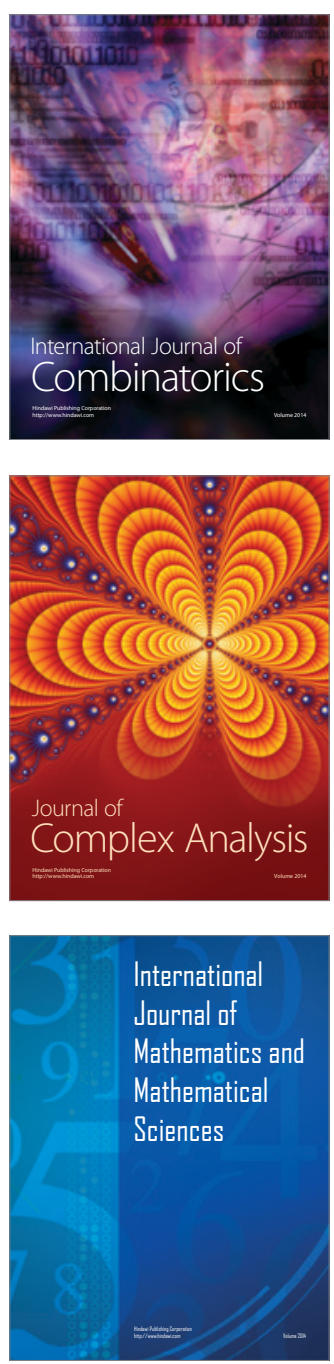
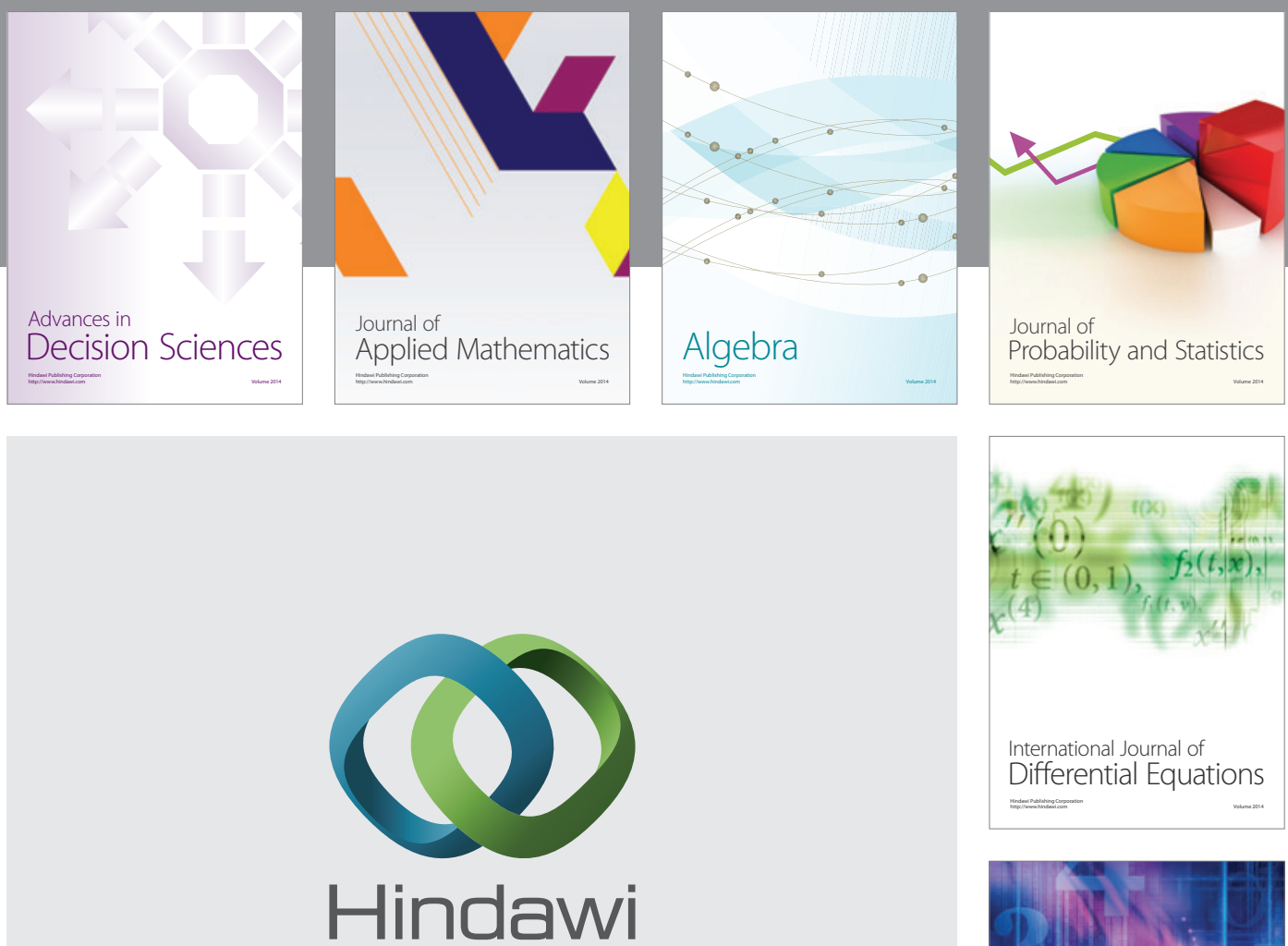

Submit your manuscripts at http://www.hindawi.com
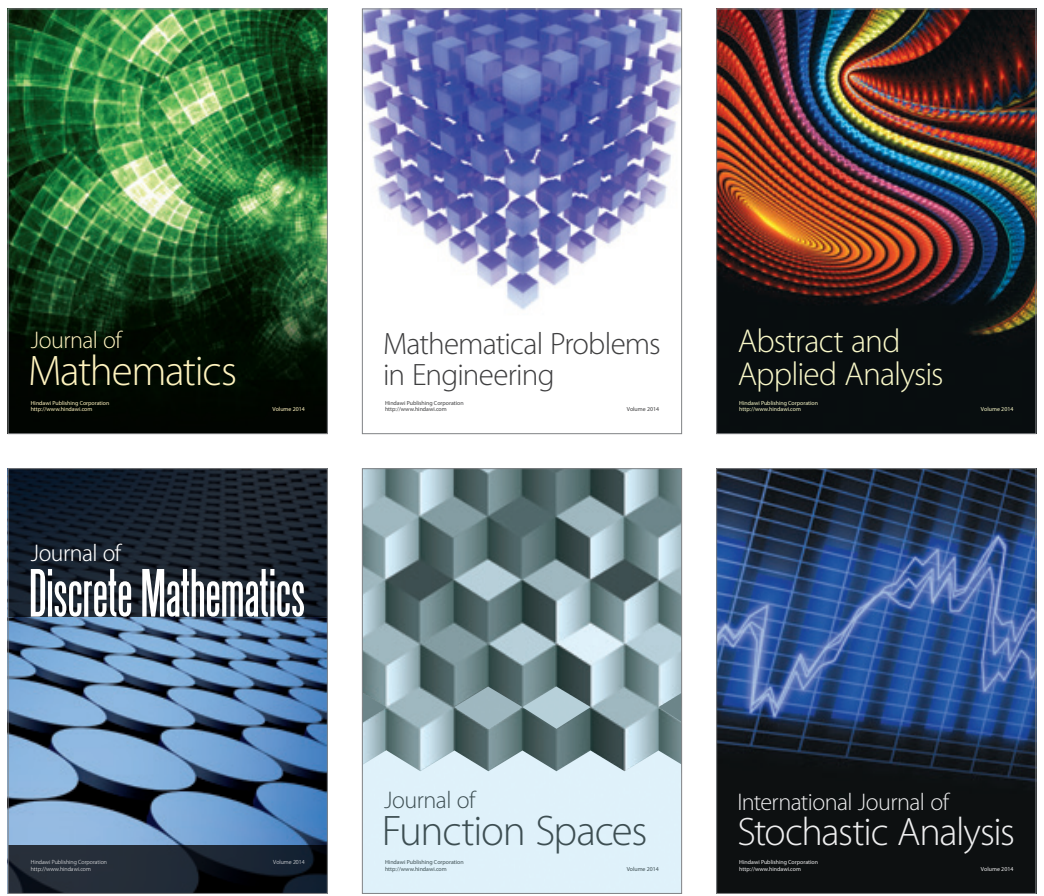

Journal of

Function Spaces

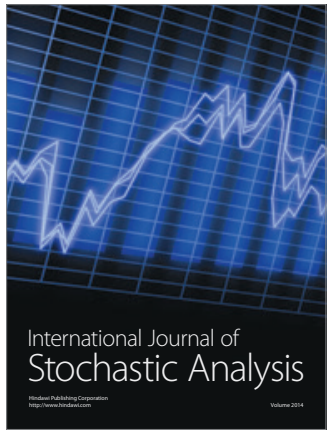

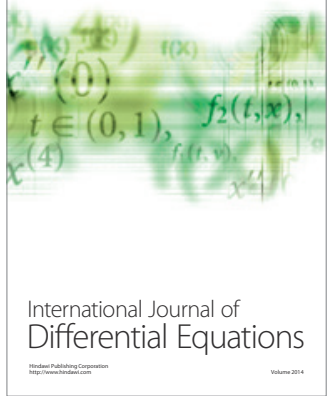
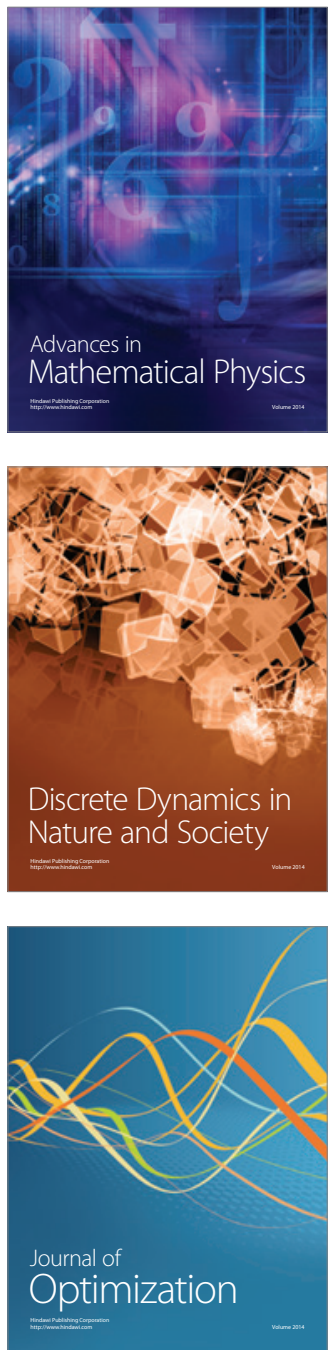